\title{
Research on the Choice of Enterprise Management and Control Mode
}

\author{
Xiaobin Lin, Jianhui Liao and Hanxiong Xiao \\ State Grid Energy Research Institute CO., LTD., Beijing, China
}

\begin{abstract}
There are three main types of corporate management and control. They are strategic management and control, financial management and control, operation management and control. The choice of enterprise management and control mode is affected by many factors. Enterprises generally establish an appropriate management and control system based on factors such as functional positioning and business characteristics. With changes in internal and external environments or corporate strategic transformations, dynamic adjustment of corporate management and control models. The management and control model of Chinese enterprises must conform to the trends and characteristics of state-owned enterprise reform and industrial transformation.
\end{abstract}

Keywords: Management and Control Mode; Strategic Management and Control; Financial Management and Control; Operation Management and Control.

\section{Introduction}

The choice of a group company's management and control model for its subsidiaries is affected by many factors, which are not only related to the national system, law, culture, economic and social development level and other macro factors, but also related to the industrial characteristics involved in the enterprise group and the evolution history of the enterprise group related. Although there is no uniform standard for the division of enterprise management and control models, basically according to the degree of decentralization, the more common ones can be divided into three basic management and control models. They are strategic management and control, financial management and control, operation management and control.

\section{Strategic management and control}

\subsection{Features of this mode}

This is a mode of management and control between centralization and decentralization. Its basic characteristics are: First, the entire group has a clear industry choice, especially a clear main business. The parent company of the group pursues the optimization and coordinated development of the investment business's strategic portfolio, and encourages and actively takes measures to promote the cooperation of various internal business units to generate synergies. The second is the centralized decision-making of the parent company and the decentralized operation of the subsidiaries. In order to realize the strategic coordination and resource sharing of the entire group, the parent company formulates the company's overall development strategy based on the external environment and existing resources, and the business activities of the subsidiary companies must be subordinate to the parent company's overall strategic activities. Although the subsidiary, as an independent business unit and profit center, enjoys a high degree of autonomy in its business activities, the subsidiary's business plan should be based on and in line with the parent company's strategic planning and policies, and its major decisions should be consulted and reported to the parent company. Approval by the parent company. The third is that the parent company of the group not only makes unified decisions on major matters of the entire group, but also guides the business and management activities of its subsidiaries. Fourth, the main functions of the parent company of the group are asset management and capital operation, strategic coordination, team building, performance appraisal, etc. It generally does not engage in specific business activities. The 
parent company generally assesses the general manager of its subsidiary companies through a strategic indicator system, but generally does not assess the functional departments of the subsidiary. Its reward and incentive system not only attaches importance to the performance of the subsidiaries themselves, but also attaches importance to the overall performance of the group and the contributions made by the subsidiaries.

\subsection{Advantages of this mode}

The advantage of the strategic management and control model lies in the separation of decision-making and execution between parent and subsidiary companies, and the separation of property management and product management, which is conducive to the professional operation and incentives of subsidiaries; at the same time, the parent company focuses on strategic decision-making and resource deployment, and ensures the overall group through decision-making control. Development direction: A relatively flat organizational structure can reduce decision-making links, greatly improve decision-making efficiency and enterprise resilience, and is conducive to rapid replication of scale expansion for enterprises in a single industry.

\subsection{Disadvantages of this mode}

The shortcomings of this model are mainly reflected in the fact that due to the lagging and incomplete decision-making information of the group's senior management, it may lead to inefficient or even wrong decision-making, and if the strategic management coordination function is not implemented well, it may cause conflicts between parent and subsidiary companies.

At present, many well-known corporate groups in the world have adopted this control mode, such as BP, Shell, Philips, Toyota, Panasonic, Mercedes-Benz, Canon, 3M, ABB, Emerson, Metropolis, Unilever, etc.

\section{Financial management and control}

\subsection{Features of this mode}

This is a control mode with a high degree of decentralization. Enterprise groups that adopt the financial management and control model generally regard the group company department as the investment decision center, with the goal of maximizing capital value. The group's overall financial income and expenditure status and asset operation are monitored, making corresponding investment decisions, and also responsible for external in the implementation of mergers and acquisitions of enterprises, the general "capital-based" enterprise group adopts this mode of management and control. Under this management and control model, the management and control of subsidiaries by the group company is centered on asset management, and the main assessment content is to evaluate the financial performance of the operating performance based on the budget and plan prepared by each subsidiary and the comparison of the operating results of peer companies outside the group. . Group companies are generally small in scale and do not directly intervene in the operation and management of subsidiaries, and only intervene under special circumstances to ensure the completion of business objectives. For example, the Morgan Consortium and Rockefeller Consortium in the United States have mainly adopted financial management and control models.

\subsection{Advantages of this mode}

The advantages of the financial management and control model are mainly reflected in the fact that group companies and affiliated companies are mainly linked by capital and finance, with asset management and benefit analysis as the core, to assess and evaluate affiliated companies. For subsidiaries, the financial management and control mechanism helps to improve financial performance, thereby promoting the company to obtain satisfactory operating results. For companies with poor performance, they can sell their equity through the capital market at any time. 
Volume 16 (2021)

\subsection{Disadvantages of this mode}

The main disadvantage of the financial management and control model is that it may cause the group to focus too much on short-term benefits while ignoring the long-term development of the group's business.

\section{Operation management and control}

\subsection{Features of this mode}

The most prominent feature of the operation management and control type is process control, which is the company's management and control mode with the highest degree of centralized authority. Under the operation management and control model, its group company acts as the business decision center and production management center. In order to ensure the realization of the group's strategic goals and the achievement of organizational goals, the group company does everything from the formulation of the strategic plan to the implementation of production operations or specific businesses. No matter what. This model requires a high degree of similarity and correlation between the businesses of each subsidiary to ensure that the resource status, management experience, and skills of the group headquarters can meet the needs of controlling the entire group enterprise. Enterprise groups that adopt this type of control are often engaged in large-scale product production or network-based natural monopoly businesses, such as electricity, telecommunications, railways, steel, and coal. For example, Baosteel, a well-known steel production enterprise in my country, has basically adopted an operation management and control model in its steel production business, carried out centralized and unified management, and supervised the headquarters functional organization to carry out on-site management.

\subsection{Advantages of this mode}

The advantages of the operational management and control model are mainly reflected in the fact that the group, as the parent company, can mobilize the various resources of its subsidiaries in a unified manner, and can achieve overall optimization of operations and form the advantages of integrated operations.

\subsection{Disadvantages of this mode}

The shortcomings of the operational management and control model are mainly reflected in the fact that the headquarters of the group enterprise undertakes a large amount of operation and management work, which leads to a high degree of concentration of subordinate subsidiaries on the business objectives assigned by the parent company of the group, and rigid management of the subordinate enterprises. In the face of frequent changes in the market economy, the management staff of the group's subsidiaries lack flexibility and lack the enthusiasm for active operation and management in the face of the market.

\section{The experience of the enterprise choosing the management and control mode}

\subsection{Based on factors such as functional positioning and business characteristics, the company establishes an appropriate management and control system}

These three control modes have different applicable conditions, and each has its own advantages and disadvantages. Among the various factors that affect the group's management and control model, the group's functional positioning, business characteristics and other factors play a decisive role. The company's management and control model must be compatible with the functional positioning and business characteristics. For example, GE has chosen a decentralized management and control model based on the characteristics of its large business industry span, and established a management and control system based on its own product characteristics and customer needs. In 
fact, enterprise group management and control in practice often adopt a comprehensive mode dominated by one mode. For example, Shanghai Baosteel Group, in addition to adopting a management and control model for its steel production business, the group headquarters adopts a strategic control model for businesses such as finance and trade.

\subsection{Companies will dynamically adjust their management and control models with changes in internal and external environments or corporate strategic transformations}

Temasek Group adjusts its corporate capital operation model in a timely manner in accordance with the needs of market development. GE adjusted its management and control system in a timely manner based on changes in the internal and external environment. Chinalco adheres to the group's strategic management and control, sector operation management, and entity enterprise production and management management and control model, and continues to strengthen the sector and strengthen the professional operation and management responsibilities of the sector. However, in the special period of turning losses and getting out of difficulties, it adopts more operation management and control models. It can be seen that the management and control model of an enterprise is not static in practice, but needs to be dynamically adjusted according to changes in the internal and external environment or the transformation and development of the enterprise.

\subsection{The business management and control model of Chinese enterprises must conform to the trends and characteristics of state-owned enterprise reform and industrial transformation}

In recent years, with the deepening of the reform of state-owned enterprises, the rise of new technological revolutions and industrial reforms, the following new trends have emerged in the management and control of Chinese enterprise groups: First, state-owned enterprises implement classified reforms, classified development, classified supervision, and classified responsibility, Classification assessment, the internal state-owned enterprise group should classify the business according to the functional positioning and so on. The second is that in terms of the internal structure of enterprises, platformization and decentralization have emerged, and the traditional hierarchical structure has changed to a loose structural model. The third is the study of the gradual transition from the position of the group company to the function of the subsidiary in terms of the status of the parent subsidiary. Therefore, the business management and control of Chinese enterprises should also consider the new trends in the management and control of these state-owned enterprise groups.

\section{Conclusion}

This article studies the advantages and disadvantages of the three corporate governance models. Different types of companies can choose corresponding models. China is advancing the reform of state-owned enterprises. Improving corporate governance is an important reform measure. State-owned enterprises need to accelerate the reform of the management and control model.

\section{Acknowledgements}

The authors gratefully acknowledge the financial support from the SGCC Technology Project-Research on Company Capital Operation Analysis Technology and Reform Mode under the New Reform Situation.

\section{References}

[1] Ouchi. The relation between organization structure and organization control [J]. Administration Science Qarterly, 1977, 22 (1): 95 - 113. 
Volume 16 (2021)

[2] J.F.Weston K.S.Chung S.E.Hoag. Mergers, Restructuring, and Corporate Control [M]. Printice Hall Inc., 1996.

[3] R.N.Anthony V.Govindarajan. Management Control System [M]. McGraw Hill Companies, 1998. 